\title{
Declaración de Estambul en relación al tráfico de órganos y turismo en trasplante
}

\author{
Autoría de los participantes de la Cumbre Internacional en \\ Tráfico de Ó rganos y Turismo en Trasplante, realizada en \\ Estambul, Turquía del 30 de abril al 2 de mayo de 2008. \\ D ocumento respaldado por The Transplantation Society e \\ International Society of Nephrology y traducido del \\ original en inglés (con autorización de los autores) \\ por el Dr. Mario U ribe, Presidente de la Sociedad \\ Chilena de Trasplante
}

\section{Istambul Declaration on organ trafficking and transplant tourism}

This is a translation into Spanish, done by Mario Uribe, M.D., F.A.C.S., and authorized by the Conference Organization, of the official statements signed by The Transplantation Society, The International Society of Nephrology and the representatives who participated at a WHO sponsored Conference held in Istambul, Turkey, April 30 to May 2, 2008 (Rev Méd Chile 2009; 137: 1117-21).

(Key words: Ethics, medical; Organ transplantation; World Health Organization)

Recibido y aprobado el 9 de julio, 2009.

$\mathrm{E}$ trasplante de órganos, uno de los milagros médicos del siglo XX, ha prolongado y mejorado la vida de cientos de miles de pacientes en todo el mundo. Muchos grandes avances científicos y clínicos de dedicados profesionales de la salud, así como innumerables actos de generosidad de donantes de órganos y sus familias, han hecho del trasplante no sólo una terapia que permite salvar vidas sino un deslumbrante símbolo de la solidaridad humana. Sin embargo, estos logros han sido opacados por numerosos reportes de tráfico en seres humanos, que han sido usados como fuentes de órganos y de pacientes-turistas

Correspondencia a: Dr. Mario Uribe. E mail: muribem@clc.cl de países ricos que viajan al extranjero para comprar órganos a la gente pobre. En el año 2004, la Organización Mundial de la Salud hizo un llamado a sus países miembros para "tomar medidas para proteger a los grupos más pobres y vulnerables del turismo en trasplante y de la venta de órganos y tejidos, llamando la atención sobre el inmenso problema del tráfico internacional de órganos y tejidos" 1 .

Para enfocar los urgentes y crecientes problemas de ventas de órganos, turismo en trasplante y tráfico de donantes de órganos en el contexto de escasez de los mismos, se convocó a un encuentro de más de 150 representantes de sociedades científicas y cuerpos médicos de todo el mundo, representantes de gobiernos, cientistas sociales y expertos en ética. Este encuentro se realizó en 
Estambul, del 30 de abril al 2 de mayo de 2008. El trabajo preparatorio para el encuentro fue realizado por el Comité Directivo convocado por The Transplantation Society (TTS) y la International Society of Nephrology (ISN) en Dubai, en diciembre de 2007. El Comité preparó un borrador de la Declaración al cual se le dio amplia difusión, el que fue revisado considerando los comentarios recibidos. En el encuentro, el borrador revisado fue corregido por grupos de trabajo para, posteriormente, ser finalizado en reuniones plenarias.

Esta Declaración representa el consenso de los participantes en el encuentro. Todos los países necesitan un marco legal y profesional para efectuar la donación de órganos y actividades de trasplante, así como un sistema regulatorio transparente que vele por la seguridad del paciente y el receptor y que refuerce los estándares y prohibiciones de prácticas no éticas.

Las prácticas reñidas con la ética son, en parte, una consecuencia indeseable de la escasez de órganos para trasplante en todo el mundo. En efecto, cada país debe esforzarse para contar con programas que permitan prevenir la insuficiencia funcional de órganos, así como programas de trasplante en caso que éstos fallen. Estos últimos, deben ser implementados de manera tal que puedan proveer órganos que satisfagan la necesidad de trasplante de los residentes de un determinado país, ya sea localmente o a través de sistemas de cooperación regional. El potencial terapéutico de la donación de órganos cadavéricos debe ser maximizado, no sólo para la utilización de riñones sino también para otros órganos, de acuerdo a las necesidades de trasplante de cada país. Los esfuerzos para iniciar o mejorar la donación de órganos provenientes de cadáver son esenciales para minimizar la presión sobre donantes vivos. Los programas educacionales son necesarios para considerar las barreras, malos entendidos y desconfianzas que, con frecuencia, impiden la meta de obtener suficientes órganos provenientes de cadáveres. Los programas exitosos de trasplante también dependen de la existencia de un adecuado sistema de salud y de su infraestructura.

El acceso a la salud es un derecho humano, pero con frecuencia no es una realidad. Los cuidados sanitarios de los donantes vivos antes, durante y después de la cirugía -como se describe en los informes de los foros internacionales organizados por TTS en Amsterdam y Vancouver ${ }^{2-4}$ no son menos importantes que los cuidados del paciente trasplantado. Los resultados exitosos para un receptor nunca podrán justificar el daño de un donante vivo; por el contrario, los casos de trasplante con donante vivo deben ser considerados como un éxito sólo cuando tanto el receptor como el donante han tenido un desenlace positivo.

Esta Declaración está basada en los principios de la Declaración Universal de Derechos Humanos ${ }^{5}$. La amplia representación en el Encuentro de Estambul refleja la importancia de la colaboración internacional y de los consensos globales para mejorar la donación y las acciones relacionadas con trasplante. La Declaración debe ser entregada tanto a organizaciones de profesionales consideradas relevantes como a las autoridades sanitarias de los diferentes países para su consideración. El legado del trasplante no debe ser un empobrecimiento de las víctimas del tráfico de órganos y el turismo en trasplante sino más bien una celebración del regalo de una nueva salud que un individuo entrega a otro.

\section{Definiciones:}

El "tráfico de órganos" es la obtención, transporte, transferencia, albergue o recepción de personas vivas o fallecidas o de sus órganos por medio de amenazas, uso de la fuerza o cualquier forma de coerción, secuestro, fraude, engaño, abuso de poder o de vulnerabilidad, tanto por el que entrega el órgano como por el que lo recibe, incluyendo pago por terceros o beneficios para lograr la transferencia o el control de un potencial donante, con el propósito de explotación para extraer órganos para trasplante ${ }^{6}$.

"Comercio de órganos" es una práctica en la cual un órgano es tratado como un bien económico que puede ser comprado, vendido o utilizado como mercancía.

"Viaje para trasplante" es el traslado de donantes de órganos, receptores o profesionales relacionados con trasplante que cruzan fronteras jurisdiccionales con el objetivo de realizar trasplantes. Los viajes para trasplante se convierten en "Turismo en trasplante" si es que involucran tráfico de órganos o la comercialización de los mismos o de otros recursos como profesionales o centros de trasplante dedicados a entregar tras- 
plantes a pacientes del extranjero, minando de esta manera la capacidad del país para entregar adecuados servicios de trasplante para su propia población.

\section{Principios:}

1. Los gobiernos nacionales, trabajando en colaboración con organismos internacionales y organizaciones no gubernamentales, deben desarrollar e implementar programas adecuados para evaluar, prevenir y tratar insuficiencias funcionales de órganos. Estos deben incluir:

a) El avance en investigación básica y clínica.

b) Programas efectivos basados en normas internacionales para tratar y mantener pacientes con enfermedades terminales, tales como programas de diálisis para pacientes con falla renal, con el objeto de disminuir la morbimortalidad, así como programas de trasplantes para tratar dicha enfermedad.

c) El trasplante de órganos es el tratamiento de preferencia para pacientes con órganos insuficientes, médicamente susceptibles de ser trasplantados.

2. Cada país o jurisdicción debe desarrollar e implementar una legislación adecuada para reglamentar la extracción de órganos provenientes de donantes vivos y cadavéricos y una práctica de trasplantes de acuerdo a estándares internacionales.

a) Deben desarrollarse e implementarse políticas y procedimientos para maximizar el número de órganos disponibles para trasplantes, de acuerdo a los principios previamente mencionados.

b) La práctica de donación y trasplante requiere regulación y supervisión por las autoridades de salud de cada país para asegurar transparencia y seguridad.

c) La supervisión requiere un registro nacional o regional para incluir tanto los donantes vivos como cadavéricos.

d) Los elementos claves para asegurar programas efectivos incluyen educación y conciencia pública, educación y entrenamiento de profesionales de la salud con responsabilidades definidas y acreditación para todos los interesados en un sistema nacional de donación y trasplante.
3. Los órganos para trasplantes deben ser distribuidos en forma ecuánime entre los potenciales receptores de países y jurisdicciones, sin considerar género, raza, religión, condición social o financiera.

a) Las consideraciones financieras o de ganancias económicas de cualquier tipo no deben influir en la aplicación de las normas relevantes de distribución.

4. El principal objetivo de las políticas de trasplantes y sus programas deben ser óptimas en el corto y largo plazo y deben contar con sistemas médicos que aseguren en el tiempo la salud de donantes y receptores.

a) Las consideraciones financieras o de ganancias materiales de cualquier tipo no pueden pasar a llevar las consideraciones primarias de salud y bienestar para donantes y receptores.

5. Las jurisdicciones, países y regiones deben esforzarse para asegurar la autosuficiencia en la donación de órganos, proveyendo un número suficiente de órganos para los residentes que lo precisen, provenientes del país o del sistema de cooperación regional.

a) La colaboración entre países no es incompatible con un sistema de autosuficiencia nacional mientras los proyectos de colaboración protejan a los más vulnerables, promuevan la equidad entre poblaciones de donantes y receptores y no violen estos principios.

b) El tratamiento de pacientes que provengan fuera del país o jurisdicción sólo es aceptable si no disminuye la capacidad del país para entregar servicios de trasplante a su propia población.

6. El tráfico de órganos y el turismo en trasplante violan los principios de equidad, justicia y respeto de la dignidad humana y deben ser prohibidos. Debido a que la comercialización en trasplante perjudica a los donantes más pobres y vulnerables esto lleva inexorablemente a la inequidad e injusticia y debe ser prohibido. En la resolución №4.425 de la Asamblea Mundial de la Salud se hace un llamado a los países para prevenir la compra y venta de órganos para trasplante.

a) Las prohibiciones de estas prácticas deben incluir una prohibición de todo tipo de 
propaganda (incluyendo medios escritos o electrónicos) solicitud o transacción con el objeto de comercialización para trasplante, tráfico de órganos o turismo en trasplante.

b) Dichas prohibiciones deben incluir sanciones para actos -tales como evaluación médica de donantes, órganos o trasplante de órganos- que ayuden, fomenten o usen los productos de tráficos de órganos o turismo en trasplante.

c) Las prácticas que inducen a los individuos o grupos vulnerables (tales como analfabetos, personas en extrema pobreza, inmigrantes indocumentados, prisioneros $\mathrm{O}$ asilados políticos o económicos) para ser donantes vivos de órganos son incompatibles con la meta de combatir el tráfico de órganos, el turismo en trasplante y el comercio en trasplante.

\section{Propuesta:}

En consistencia con estos principios, los participantes de la Cumbre de Estambul sugieren las siguientes estrategias para aumentar la disponibilidad de órganos, prevenir el tráfico de órganos, la comercialización y turismo en trasplante y fomentar aquellos legítimos programas de trasplante orientados a salvar la vida de los pacientes.

Para responder a la necesidad de aumentar la donación cadavérica:

1. Los gobiernos, en colaboración con las instituciones de salud, profesionales y organismos no gubernamentales, deben adoptar las acciones necesarias para aumentar la donación de órganos provenientes de donantes cadáveres. Deben adoptarse medidas para derribar obstáculos y desincentivos a la donación de órganos provenientes de cadáveres.

2. En países sin una establecida donación de órganos cadavéricos debe establecerse una legislación para iniciar la donación cadavérica y crear una infraestructura en trasplante que satisfaga el potencial de donación cadavérica de dicho país.

3. En todos los países en los cuales se ha iniciado la donación de órganos cadavéricos, el potencial terapéutico de dicha donación de órganos cadavéricos deber ser maximizado.

4. Los países con programas establecidos de donación y trasplante son motivados para compartir la información, experiencia y tecnología con aquellos países que buscan con esfuerzo mejorar la donación de órganos.

Para asegurar la protección y la seguridad de los donantes vivos y un adecuado reconocimiento de sus actos heroicos mientras se combate el turismo en trasplante, tráfico de órganos y comercio en trasplante, se debe considerar:

1. El acto de donación debe ser considerado heroico y valorado como tal por los representantes de los gobiernos y de las organizaciones de la sociedad civil.

2. La determinación de la adecuada condición médica y psicosocial de un donante vivo debe ser guiada por las recomendaciones de los Foros de Amsterdam y Vancouver ${ }^{2-4}$.

a) Los mecanismos para el consentimiento informado deben incorporar definiciones para evaluar la adecuada comprensión del donante, incluyendo el impacto psicológico de este proceso.

b) Todos los donantes deben tener una evaluación psicosocial por profesionales expertos en salud mental, como parte de la evaluación general.

3. El cuidado de los donantes de órganos, incluyendo aquellos que han sido víctimas de tráfico de órganos, comercio en trasplante y turismo en trasplante es una responsabilidad crítica para todas aquellas jurisdicciones que sancionarán los trasplantes de órganos utilizando dichas prácticas.

4. Los sistemas y estructuras deben asegurar estandarización, transparencia y regulación para apoyar la donación.

a) Deben establecerse mecanismos que aseguren la transparencia del proceso y del seguimiento.

b) Debe obtenerse consentimiento informado tanto para la donación como para el control y seguimiento.

5. La entrega de cuidados incluye apoyo médico y psicosocial desde el momento de la donación y para cualquier consecuencia a corto o largo plazo relacionadas con la donación de órganos:

a) En las jurisdicciones y países que no tienen un sistema de seguro universal de salud, la entrega de seguros de vida, discapacidad y 
de salud relacionada con la donación es un requerimiento necesario en el cuidado del donante.

b) En aquellas jurisdicciones que tienen seguros universales de salud, los servicios gubernamentales deben asegurar a los donantes un acceso a cuidados médicos adecuados, relacionados con el evento de donación.

c) La cobertura de los seguros de vida y salud, así como las oportunidades de empleo de aquellas personas que donan órganos no pueden quedar comprometidas.

d) A todos los donantes debe ofrecérseles apoyo psicosocial, como un elemento estándar de seguimiento.

e) En el caso de falla orgánica del donante, éste debe recibir:

i) Cuidados médicos de apoyo, incluyendo diálisis en caso de falla renal, y

ii) Prioridad de acceso a un trasplante de acuerdo a leyes de distribución de órganos existentes, ya sean aplicadas a donación viva o cadavérica.

6. El adecuado reembolso de los gastos documentados, relacionados con la donación no se consideran un pago por el órgano, sino que constituyen parte de los legítimos costos del tratamiento del receptor.

a) Este reembolso debe, usualmente, ser hecho por la parte responsable de los costos del tratamiento de trasplante del receptor (sea éste el Ministerio de Salud o una compañía aseguradora).

\section{REFERENCIAS}

1. World Health Assembly Resolution 57.18, Human organ and tissue transplantation, 22 May 2004, Disponible en: http://www.who.int/gb/ebwha/ pdf_files/WHA57/A57_R18-en-pdf

2. The Ethics Committee of the Transplantation Society. The Consensus Statement of the Amsterdam Forum on the Care of the Live Kidney Donor. Transplantation 2004; 78: 491-2.

3. Barr Ml, Belghiti J, Villamil FG, Pomfret EA, Sutherland DS, Gruessner RW et al. A Report of the Vancouver Forum on the Care of the live organ donor: lung, liver, pancreas, and intestine data and medical guidelines. Transplantation 2006; 81: 1373-85. b) Los costos relevantes y los gastos deben ser calculados y administrados usando una metodología transparente, de acuerdo a las normas y reglamentos del país.

c) El reembolso de los costos aprobados involucrados debe ser hecho directamente a la parte que entrega el servicio (como, por ejemplo, el hospital que provee el cuidado médico del trasplantado).

d) El reembolso de los ingresos perdidos por el donante, así como gastos menores deben ser administrados por la agencia que provee el trasplante, más que un pago directo del receptor al donante.

7. Gastos legítimos que pueden ser reembolsados cuando se encuentran debidamente documentados incluyen:

a) El costo de cualquier evaluación médica y psicológica de potenciales donantes vivos que son excluidos de la donación (por ejemplo: debido a causas médicas o inmunológicas descubiertas durante el proceso de donación).

b) Los costos incurridos en organizar y efectuar las fases pre, peri y post operatoria del proceso de trasplante (por ejemplo: llamadas de larga distancia, viajes, alojamiento y gastos de alimentación).

c) Gastos médicos incurridos para los cuidados del donante post alta.

d) Pérdida de ingresos relacionados con el proceso de donación (de acuerdo con las normas nacionales).

4. Pruett Tl, Tibell A, Alabdulkareem A, Bhandari M, Cronon DC, Dew MA et al. The Ethics Statement of the Vancouver Forum on the live lung, liver, pancreas, and intestine donor. Transplantation 2006; 81: 1386-7.

5. Universal Declaration of Human Rights, adopted by the UN General Assembly on December 10, 1948, Disponible en: http://www.un.org/Overview/ rights.html

6. Based on Article $3^{\underline{a}}$ of the Protocol to Prevent, Suppress and Punish Trafficking in Persons, Especially Women and Children, Supplementing the United Nations Convention Against Transnational Organized Crime 2000. Disponible en: htpp:// www.uncjin.org/Documents/Conventions/dcatoc/ final_documents_2/convention_\%20traff_eng.pdf 